\title{
Medios y Género: Nuevos retos globales
}

CP 2015 , Vol.4-Nº7, pp. 141-143. ISSN 2014-6752. Girona (Catalunya). FERNÁNDEZ GARCÍA, Nuria: Medios y Género: Nuevos retos globales. Recibido: 30/11/2015 - Aceptado: 02/12/2015

\author{
Media and Gender: A Scholarly Agenda for the Globall Alliance on \\ Media and Gender \\ Aimée Vega Montiel (Ed.) \\ Paris, Francia \\ Publicado por United Nations Educational, Scientific and Cultural \\ Organization (UNESCO) 2014. \\ 94 páginas \\ ISBN: 978-92-3-100029-4
}

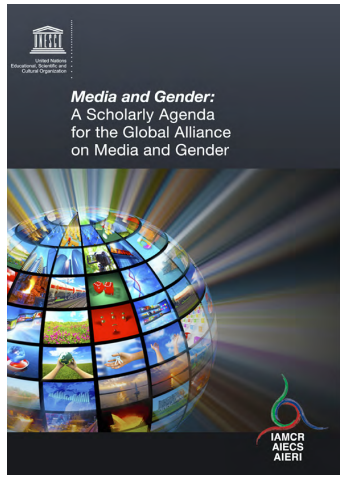

\section{Nuria FERNÁNDEZ GARCÍA}

Investigadora del Gabinete de Comunicación y Educación (Departamento de Periodismo y de Ciencias de la Comunicación, UAB).nuria.fernandez@uab.cat

Este volumen que aquí reseñamos es fruto de la creación de la Global Alliance on Media and Gender (GAMAG) que busca conseguir un diálogo constructivo entre medios y sociedad civil y promover unos medios y un entorno comunicativo con perspectiva de género.

Media and Gender: A Scholarly Agenda for the Global Alliance on Media and Gender es un texto recopilatorio que propone una agenda de investigación para el GAMAG. Elaborado por la International Association for Media and Communication Research (IAMCR) y publicado por la UNESCO, cuenta con artículos firmados por autoras tan renombradas como Margaret Gallagher, Annabelle Sreberny, Carolyn Byerly o Karen Ross, entre otras. Es este un libro de lectura sencilla de apenas 94 páginas que resulta de gran interés para toda aquella persona interesada en la relación entre género y medios de comunicación.

El volumen se divide en un bloque introductorio y cuatro secciones temáticas que tratan cuestiones como la violencia de género en los medios, el acceso de las mujeres a los medios y a la información, las políticas y estrategias de género en los medios, y la alfabetización mediática y el género.

En la primera parte del volumen, que sirve de introducción, destaca el artículo de Margaret Gallagher en el que se realiza un repaso a las aportaciones teóricas más relevantes y las investigaciones y debates existentes en torno al género y la comunicación. Así, nos encontramos con los trabajos de Gaye Tuchman, Nancy Fraser, Rosalind Gill, Carolyn Byerly o Karen Ross, al mismo tiempo que se señalan futuros retos en los que será cada vez más importante la asociación entre universidad y activismo.

A continuación, se muestra el primer bloque dedicado a la violencia de género, los medios y la información. En este bloque se pueden encontrar cuatro artículos. El primer artículo, firmado por Aimée Vega, presenta algunas de las tendencias y desafíos más importantes en la investigación sobre violencia contra las mujeres. Cómo los 
medios representan la explotación sexual es abordado por Barbara Ann Barnett que denuncia la forma superficial y limitada empleada por los medios en su cobertura. La masculinidad hegemónica en los medios es tratada en el artículo de Peter J. Kareithi donde aporta algunas ideas sobre cómo combatir las masculinidades dominantes en los medios, enfatizando la importancia de las políticas públicas, la investigación académica, la industria de medios o los programas educativos. Cierra este bloque un artículo de Annabelle Sreberny en el que se aborda la violencia contra las mujeres periodistas. La autora enumera las diferentes formas en las que tiene lugar la violencia contra las mujeres periodistas: mientras informan de acontecimientos peligrosos tales como guerras y zonas en conflicto; violencia sexual; una violencia de estado en forma de arresto arbitrario, encarcelamiento y tortura; y otras formas de violencia que las mujeres se encuentran en internet.

El segundo apartado trata, a través de cinco artículos, el acceso de las mujeres a los medios y a la información. En el primero, Carolyn Byerly destaca las relaciones de género en la profesión periodística y se pregunta hasta qué punto la entrada de las mujeres en el periodismo ha tenido éxito teniendo en cuenta la participación de las mujeres en las redacciones y en los puestos de dirección de las compañías de medios. Continuando con este análisis, Karen Ross denuncia en su artículo la escasa presencia de mujeres en los puestos de dirección. En este apartado también se pueden encontrar artículos donde se revisa las prácticas periodísticas de los últimos años (Marjan de Bruin), la presencia de mujeres en la radio comunitaria (María Eugenia Sánchez) o la brecha digital de género en el acceso de las mujeres a las nuevas tecnologías de la información y la comunicación (Cecilia Castaño).

El tercer bloque aborda las políticas y estrategias de los medios con perspectiva de género. Abre el apartado un artículo de Claudia Padovani en el que presenta un conjunto de principios guía para lograr la igualdad y la no discriminación: conceptualizar desde una perspectiva de género; cuestionar los hallazgos de los análisis sobre género y medios; reconocer las contribuciones existentes por la comunidad académica más allá de la investigación; y establecer las bases para estructurar una política y un marco de investigación con perspectiva de género. Ammu Joseph continúa con un artículo en el que utiliza la cobertura a lo largo del tiempo de las violaciones de mujeres en India para contrastar cómo ésta ha cambiado gracias a la presión de organizaciones para sensibilizar a los medios. Las barreras para incorporar la perspectiva de género en la política de medios están presentes en el artículo que cierra este bloque, firmado por Katharine Sarikakis.

Por último, el volumen finaliza con un apartado dedicado a la educación y la alfabetización mediática e informacional con perspectiva de género. En el primer artículo, Margaretha Geertsema-Sligh realiza un estado de la cuestión de la inclusión de la perspectiva de género en el periodismo y en la formación periodística. A continuación, Jad Melki y May Farah abordan la discriminación de género y el acoso sexual en los ámbitos laborales de la industria de medios. Finalmente, Alton Grizzle explora en un extenso e interesante capítulo cómo la alfabetización mediática e informacional podría ser utilizada para promover la igualdad de género en y a través de los medios.

Como he comentado al principio de esta reseña, este volumen es de fácil lectura por lo que pude ser de utilidad tanto en el ámbito académico como en empresas de medios, profesionales de los medios, el ámbito político y para la sociedad civil. Media and Gender: A Scholarly Agenda for the 
Globall Alliance on Media and Gender supone un interesante compendio de aportaciones del ámbito de la comunicación que va más allá del contenido y la representación del género en los medios. Este volumen contribuye así a tener un mayor conocimiento de la relación entre género y medios y a diseminar investigaciones que utilizan la perspectiva de género al analizar los medios de comunicación. Y, lo que resulta más importante, apunta nuevas direcciones para seguir profundizando en las investigaciones sobre medios con una perspectiva de género.

\section{Forma de citación}

FERNÁNDEZ GARCÍA, Nuria: Medios y Género: Nuevos retos globales. Revista Communication Papers, No7, páginas $\mathrm{xx}$ a $\mathrm{xx}$. Departamento de Filología y Comunicación de la Universidad de Girona. Recuperado el __ de de 2 de: http://www.communicationpapers.es 